\title{
Alternatives to immediate release tacrolimus in solid organ transplant recipients: When the gold standard is in short supply
}

\author{
Margaret R. Jorgenson $^{1}$ (D) | Jillian L. Descourouez ${ }^{1}$ (D) | Bethany L. Brady ${ }^{2}$ | \\ Lyndsey Bowman $^{3}$ | Sara Hammad ${ }^{4}$ | Tiffany E. Kaiser ${ }^{5}$ | Melissa R. Laub ${ }^{6}$ (D) | \\ Jennifer I. Melaragno ${ }^{7}$ | Jeong M. Park ${ }^{8}$ | Mary M. Chandran'
}

\author{
${ }^{1}$ Department of Pharmacy, University of \\ Wisconsin Hospital and Clinics, Madison, \\ WI, USA \\ ${ }^{2}$ Pharmacy Department, Indiana University \\ Health University Hospital, Indianapolis, \\ IN, USA \\ ${ }^{3}$ Department of Pharmacy, Tampa General \\ Hospital, Tampa, FL, USA \\ ${ }^{4}$ Department of Pharmacy, University of \\ Maryland Medical Center, Baltimore, MD, \\ USA \\ ${ }^{5}$ Department of Pharmacy, University of \\ Cincinnati Medical Center, Cincinnati, $\mathrm{OH}$ \\ USA \\ ${ }^{6}$ Department of Pharmacy, Augusta \\ University Medical Center, Augusta, GA, \\ USA \\ ${ }^{7}$ Department of Pharmacy, University of \\ Rochester Medical Center, Rochester, NY, \\ USA \\ ${ }^{8}$ Department of Clinical Pharmacy, \\ University of Michigan College of Pharmacy, \\ Ann Arbor, MI, USA \\ ${ }^{9}$ Department of Pharmacy, Children's \\ Hospital of Colorado, Aurora, CO, USA \\ Correspondence \\ Margaret R. Jorgenson, PharmD, BCPS, \\ University of Wisconsin Hospital and Clinics, \\ 600 Highland Ave, Madison, WI 53792, \\ USA. \\ Email: MJorgenson@uwhealth.org
}

\begin{abstract}
Given the current climate of drug shortages in the United States, this review summarizes available comparative literature on the use of alternative immunosuppressive agents in adult solid organ transplant recipients including kidney, pancreas, liver, lung, and heart, when immediate-release tacrolimus (IR-TAC) is not available. Alternative options explored include extended-release tacrolimus (ER-TAC) formulations, cyclosporine, belatacept, mammalian target of rapamycin inhibitors, and novel uses of induction therapy for maintenance immunosuppression. Of available alternatives, only ER-TAC formulations are of non-inferior efficacy compared to IR-TAC when used de novo or after conversion in stable kidney transplant recipients (KTRs). All other alternatives were associated with higher rates of biopsy-proven rejection, but improved tolerance from classic adverse effects of IR-TAC including nephrotoxicity and development of diabetes. While most alternative therapies are approved in KTRs, access via third-party payors is an obstacle in non-KTRs. In the setting of IR-TAC shortage, alternate therapeutic options may be plausible depending on the organ population and individual patient situation to ensure appropriate, effective immunosuppression for each patient.
\end{abstract}

\section{KEYWORDS}

anti-proliferative agent; immunosuppressant, calcineurin inhibitor (CNI); immunosuppressant, fusion proteins and monoclonal antibodies; immunosuppressant, immunosuppression/ immune modulation; immunosuppressant, mechanistic target of rapamycin (mTOR)

\section{1 | INTRODUCTION}

Tacrolimus is an immunosuppressant that exerts its activity via suppression of cellular immunity by binding to FKBP-12 to form a complex with calcineurin-dependent proteins to inhibit calcineurin phosphatase activity and subsequently $T$ lymphocyte activation. Approved by the Federal Drug Administration (FDA) under the brand name Prograf ${ }^{\circledR}$ in 1994, immediate-release tacrolimus (IR-TAC) is now considered the backbone of maintenance immunosuppressive regimens in solid organ transplantation (SOT). In the United States (US), it is reported that more than $70 \%$ of SOT recipients are initiated on a TAC-based regimen (SRTR 2018 Annual Report). The extensive use of tacrolimus is likely attributable to its superiority in prevention of allograft rejection, particularly in the 
setting of renal transplant. This benefit has been demonstrated even when comparing to the other agent in its class, cyclosporine (CYA). ${ }^{1,2}$ Given favorable allograft outcomes, IR-TAC alternatives are typically reserved for special circumstances, such as to address patient tolerability, comorbidities, and very recently, IR-TAC availability.

As of spring 2019, a manufacturing shortage of generic IR-TAC capsules has limited its access in the United States. ${ }^{3}$ The prolonged national shortage without a definite resolution timeline has created an urgent need to identify appropriate candidates for and applications of IR-TAC alternatives. The aim of this piece is to review available literature and concisely summarize the use of each IR-TAC alternative and associated outcomes with a focus on providing a comparative efficacy summary, clinical pearls, and a risk and benefit evaluation. Alternative IR-TAC options explored include extended-release formulations of TAC (ER-TAC), cyclosporine, belatacept, mammalian target of rapamycin inhibitors (mTORis), and novel application of induction therapy for maintenance immunosuppression.

\section{2 | METHODS}

A systematic review of English language articles using PubMed, the Cochrane Controlled Trials Register (1960-2019), and EMBASE (1991-2019) for studies evaluating the efficacy, safety, and dosing strategies for conversion from a IR-TAC-based immunosuppressive regimen to an alternative agent in adult (age $>18$ years) SOT recipients was conducted in September 2019. Additional studies were identified by searching bibliographies and abstracts presented at the American Transplant Congress (1990-2019). There were no restrictions on study design. Search terms included tacrolimus, cy(i) closporine, belatacept, mTOR inhibitor, sirolimus, everolimus, basiliximab, daclizumab, interleukin 2 receptor antagonists, thymoglobulin, alemtuzumab, lymphocyte-depleting induction, and calcineurin inhibitor (CNI) avoidance. When evaluating comparative efficacy, preference was given to studies directly comparing IR-TAC to the agent in question. In the setting where these studies were not available, preference was given to studies comparing similar outcomes. Eligibility assessment was performed independently in a standardized and unblinded manner by two reviewers.

\section{1 | Calcineurin inhibitor alternatives}

\subsection{1 | Extended-release tacrolimus formulations}

When IR-TAC is unavailable, substitution with an ER-TAC formulation is a desirable and logical conversion (Appendix 1). Two ER-TAC formulations are approved by the FDA for prophylaxis of organ rejection in KTRs: ER-TAC capsules (XL-TAC; Advagraf ${ }^{\circledR}$ or Astagraf $\mathrm{XL}^{\circledR}$; Astellas Pharma) and ER-TAC tablets (LCPT; Envarsus $\mathrm{XR}^{\circledR}$; Veloxis Pharmaceuticals). These agents are administered once daily by mouth in the morning, ideally on an empty stomach. ${ }^{4,5}$ Although there are data to support the use of 21- or 27-hour levels with LCPT, monitoring usually consists of 24-hour TAC trough measurement. ${ }^{4-6}$

\subsection{2 | Extended-release tacrolimus pharmacokinetics and pharmacodynamics}

Despite extended-release properties, XL-TAC and LCPT have markedly different pharmacokinetic profiles and dosing requirements. $\mathrm{XL}-\mathrm{TAC}$ is slowly released through the addition of ethylcellulose, hypromellose, and lactose monohydrate. ${ }^{4}$ Pharmacokinetic studies demonstrate similar 24-hour area under the curve (AUCO-24), time to maximum concentration (Tmax), and maximum concentration (Cmax) between IR-TAC and XL-TAC at the recommended 1:1 conversion, but higher dosages of XL-TAC may be required to maintain similar trough concentrations ( $\mathrm{Cmin}$ ) to IR-TAC. ${ }^{7}$ LCPT, a novel formulation utilizing MeltDose ${ }^{\circledR}$ technology, has enhanced solubility and bioavailability and requires lower dosing requirements compared to both IR-TAC and XL-TAC. ${ }^{5}$ Studies demonstrated a similar AUC0-24 but lower Cmax with LCPT compared to IR-TAC and XLTAC. $^{7}$ The recommended conversion ratio for LCPT is $80 \%$ of the total daily dose of IR-TAC. Similar to IR-TAC, higher doses of both XL-TAC and LCPT may be needed in African American patients. ${ }^{4,5}$

Due to its unique absorption properties, LCPT partially bypasses metabolism by CYP3A5 enzymes in the proximal intestine. ${ }^{8}$ This property is beneficial for CYPA5*1 allele expressers, which is common in African Americans and may be associated with poor outcomes. ${ }^{9,10}$ Differences in the extent of metabolism by CYP3A enzymes also make LCPT less susceptible to certain drug interactions. ${ }^{11}$ Additionally, a lower Cmax achieved by LCPT decreases peak-related side effects, such as neurotoxicities. ${ }^{12}$ Both the regulated absorption and reduction in peaks have led to speculation that use may reduce opportunistic infections, such as BK polyomavirus, but this theory requires further investigation. ${ }^{13}$ Importantly, while absorption is regulated, LCPT does not necessarily reduce trough intra-patient variability. ${ }^{14}$

\subsection{3 | Extended-release tacrolimus efficacy}

XL-TAC has been studied as both conversion from IR-TAC and de novo post-transplantation. When investigated in KTR as conversion from IR-TAC (1:1), patient and graft survival were excellent (100\% and $98.5 \%$, respectively), with low rates of biopsy-proven acute rejection (BPAR) (6\%). ${ }^{15}$ Additionally, when IR-TAC and XL-TAC were compared to CYA de novo, no difference was demonstrated in a composite endpoint of death, graft loss, BPAR, or loss to follow-up (14\%, $95.2 \% \mathrm{Cl}:-9.9 \%-4 \%$ in the XL-TAC group vs $15.1 \%, 95.2 \% \mathrm{Cl}$ : $-8.9 \%-5.2 \%$ in the IR-TAC group vs $17 \%$ in the cyclosporine group). ${ }^{16}$ A recent meta-analysis of 11 randomized controlled trials (RCTs) comparing IR-TAC to XL-TAC in KTR showed no difference in estimated glomerular filtration rate (eGFR) 12 months post-transplant (mean difference of $-0.49 \mathrm{~mL} / \mathrm{min} / 1.73 \mathrm{~m}^{2}$; 95\% $\mathrm{Cl}$ : $-2.41-1.42$ ) and 
BPAR at 6 months (RR 1.03; 95\% Cl: 0.82-1.28,) or 12 months (RR: 1.11; $95 \% \mathrm{Cl}$ : 0.88-1.40). ${ }^{17}$ Additionally, 12-month graft and patient survival were not different between groups (RR: 1.01; $95 \% \mathrm{Cl}$ : 0.99 1.03 and RR: 1.00; 95\% Cl: 0.99-1.02, respectively). Of note, one of the studies included the LCPT formulation.

$\mathrm{XL}-\mathrm{TAC}$ conversion has also been studied in pancreas and liver transplant recipients (PTR, LTR). While studies evaluating XL-TAC in PTRs are limited, one study showed a similar eGFR and a low incidence of rejection (2\%), a median of $5.5(+0.9)$ months after conversion from IR-TAC to XL-TAC. ${ }^{18}$ Patient-specific factors to consider include risk of gastroparesis leading to variable absorption, or the need for enteral administration of medications. The use of de novo $\mathrm{XL}-\mathrm{TAC}$ in PTRs has not been evaluated. Studies investigating the use of XL-TAC compared to IR-TAC in LTRs demonstrate no difference in BPAR at 24 weeks $(32.6 \%$ vs $29.3 \%, P=.354$ in the overall population) and at 12 months (29.5\% vs $26.9 \%, P=.490$ in the overall population). Patient and graft survival at 12 months were also similar between groups $(85.3 \%$ vs $85.6 \%, P=.876){ }^{19}$

The use of XL-TAC in thoracic transplant yielded comparable results to abdominal transplant. One study in heart transplant recipients, however, demonstrated a significantly lower incidence of rejection 2 years after conversion (pre-conversion: 7.6 per 100 patient-years vs postconversion: 2.1 per 100 patient-years; $P<.0001) .{ }^{20}$ Study of de novo use in thoracic transplant patients found no difference in rejection rates. ${ }^{21}$ Additionally, no differences in survival or infection have been seen across studies. ${ }^{20-22}$ Acknowledging limited data, the use of XL-TAC in the heart transplant recipients appears safe, with no difference in clinical outcomes. Few studies exist, which compare XL-TAC to IR-TAC in lung transplant recipients. ${ }^{23-25}$ One study in 12 cystic fibrosis (CF) patients after lung transplantation found no episodes of rejection up to two years postconversion from IR-TAC to XL-TAC, despite a $28 \%-67 \%$ increased dose requirement in $82 \%$ of the patients. ${ }^{24}$ Given these data, CF patients may require higher doses of XL-TAC compared to IR-TAC, although this has been debated. ${ }^{25}$

Studies investigating LCPT have shown similar outcomes compared to IR-TAC in adult KTR in the de novo and conversion settings. A study of 543 adult KTRs randomized to de novo LCPT versus IR-TAC demonstrated similar efficacy failure rates (LCPT $18.3 \%$ vs IR-TAC 19.6\%; 95\% Cl: -7.94, 5.27\%) at 12 months. ${ }^{26}$ In addition, delayed graft function rates were similar, despite higher early troughs in the LCPT group. ${ }^{26} \mathrm{~A}$ follow-up study of 507 subjects demonstrated the non-inferiority of LCPT failure rate was maintained at 24 months (LCPT 23.1\% versus IR-TAC 27.3\%; 95\% Cl: -4.2, 4.2). ${ }^{27}$ A study of 324 adult KTR approximately two years after transplant randomized to convert from IR-TAC to LCPT versus remain on IRTAC showed similar efficacy failure rates between groups up to 12 months after conversion (LCPT $2.5 \%$ vs IR-TAC $2.5 \%$; $95 \% \mathrm{Cl}$ : $-4.2,4.2) .{ }^{28}$ Although no outcome differences were shown in these studies, a pooled post hoc analysis of the 12-month de novo and conversion results showed that African American patients and patients $>65$ years old using LCPT had lower rates of treatment failure compared to IR-TAC. ${ }^{29}$
Two conversion studies and one de novo study of LTRs suggest no differences in safety or efficacy with LCPT as compared to IRTAC or XL-TAC. ${ }^{30-32}$ A case series of eight PTRs found that LCPT conversion was well tolerated and led to reduction in adverse drug effects (ADEs) that led to conversion. In this small population, less aggressive empiric adjustments from IR-TAC to LCPT were needed than suggested by the manufacturer. ${ }^{33}$ Limited data exist for LCPT in thoracic transplant recipients. A pharmacokinetic study of 20 stable lung transplant recipients converted from XL-TAC to LCPT demonstrated the conversion to be safe and effective up to six months after transplant. ${ }^{34}$ No published studies in heart transplant recipients were identified, although one trial is ongoing. ${ }^{35}$

Although not extensively studied in LTR and PTRs, the lower Cmax of LCPT compared to IR-TAC may be a unique advantage in this population. Reduced risk of neurotoxicity is attractive given pre-existing neurologic issues due to the primary disease leading to transplantation and more complex postoperative courses.

Extended-release tacrolimus is not available as generic products, so out-of-pocket costs and insurance coverage are often variable. Studies performed in Europe have, however, demonstrated a cost-benefit for LCPT due to lower dosing requirements. ${ }^{31,36}$ Adherence, as assessed by validated questionnaires, may also be improved with once-daily dosing based on two studies of transplant recipients converted from IR-TAC to XL-TAC. ${ }^{37,38}$ As of January 2020, patient assistance remains available through the drug manufacturer of LCPT for qualifying patients in the United States. Overall, approval is challenging in the setting of non-KTRs. Insurers often require prior authorization as well as written documentation of neurotoxicity. Trough variability has not been an approved indication by insurance companies, as this has not been a demonstrated benefit of LCPT. Although many may require "failure" of CYA or an mTORi documentation, this can often be overcome with peer-to-peer communication or appeal.

In summary, ER-TAC has shown non-inferior efficacy compared to IR-TAC when used de novo or after conversion in stable KTRs. They have not been associated with increased nephrotoxicity and are possibly associated with improved adherence. Although not FDA-approved in non-KTRs, available data suggest that they are also safe and effective in these populations. LCPT may have the additional benefits of less erratic pharmacokinetics and lower $\mathrm{Cmax}$ concentrations, thereby improving neurotoxicity compared to IRTAC. Limited payor coverage of extended-release preparations is the primary barrier to utilizing these agents.

\subsection{4 | Cyclosporine}

If an IR-TAC product is unavailable, substitution with an alternative $\mathrm{CNI}$ is logical. The approval of cyclosporine (CYA) revolutionized transplant medicine with its cell-mediated specificity and marked improvement in rejection rates and one-year graft survival. ${ }^{39}$ Currently, CYA is FDA-approved for the prophylaxis of organ rejection in KTRs, LTRs, and heart recipients. Two forms of CYA are 
available as non-modified and modified preparations, which are not interchangeable.

Despite early widespread success with CYA, use has been largely replaced by IR-TAC due to greater immunosuppressive potency, reduced intra-patient pharmacokinetic variability, improved rates of rejection, and possibly superior allograft survival. ${ }^{40}$ Many studies and meta-analyses comparing IR-TAC to CYA across organ types have demonstrated such findings; however, existing studies have also shown conflicting results. ${ }^{41} \mathrm{~A}$ meta-analysis performed by Webster and colleagues demonstrated that using IR-TAC rather than CYA in 100 KTRs prevents acute rejection in 12 patients (RR: 0.69, $95 \% \mathrm{Cl}: 0.60$ to 0.79 ) and graft loss in two patients (RR: $0.56,0.36$ to 0.86 ) in the first post-transplant year. ${ }^{1}$ IR-TAC benefits are maintained even when targeting lower trough concentrations to minimize nephrotoxicity, as demonstrated in the ELITE-Symphony trial. This study found low-dose IR-TAC when compared to both low-dose and standard-dose CYA to be associated with lower rates of rejection $(12.3 \%, 24 \%$, and $25.8 \%, P<.001)$ and superior renal function, GFR (mL/min) $(65.4,59.4,57.1, P<.001) 1$ year post-transplant. ${ }^{42}$ In LTRs, a meta-analysis of RCTs published since 2000 showed IRTAC was superior to CYA in terms of patient mortality (RR with CYA 1.26, 1.01-1.58) and hypertension (RR with CYA 1.26, 1.07-1.47), while CYA was superior in terms of new-onset diabetes after transplant (NODAT). No significant differences were identified in graft loss or acute rejection. ${ }^{2}$ IR-TAC was also more effective than CYA in preventing moderate or severe kidney or pancreas rejection (3\% vs $28 \%, P=.009$ ) after pancreas-kidney transplantation in a 3-year study. ${ }^{43}$ It also provided superior pancreas survival (89.2\% vs $72.4 \%$; $P=.002$ ) and reduced the risk of pancreas graft thrombosis. Similar findings have been demonstrated in cardiothoracic transplant in meta-analyses of RCTs with comparable 1-year survival between agents (heart $P=.11$, lung $P=.88$ ), but increased rates of NODAT (heart $P=.003$, lung $P=.03$ ) and reduced incidence of 1-year graft rejection attributed to TAC (heart $P=.04$, lung $P=.04$ ). ${ }^{44,45}$

Although CNIs have significantly improved transplant outcomes, ADEs associated with these agents can ultimately compromise longterm patient and graft outcomes. IR-TAC shares many ADEs with CYA, including nephrotoxicity, neurotoxicity, and infectious complications. Beyond these toxicities, the CNIs have differing ADE profiles that help guide practitioners in selection between agents. CYA increases cardiovascular risk with a greater incidence of hypertension and hyperlipidemia, whereas IR-TAC is associated with a greater risk of NODAT. ${ }^{2}$

In mycophenolate mofetil (MMF)-treated organ transplant recipients, lower mycophenolic acid (MPA) plasma concentrations have been found with CYA compared to TAC-based regimens. This is the result of CYA-mediated inhibition of MPA glucuronide conjugate (MPAG) biliary excretion via the multidrug resistance-associated protein 2 (MRP2) leading to decreased enterohepatic recirculation, and thus decreasing the "second MPA peak" of MMF pharmacokinetics. ${ }^{46}$ Compared with standard-dose CYA, patients receiving lowdose IR-TAC or low-dose sirolimus (SRL) had greater concentrations of MPA and its active metabolite at various time points $(P<.05) .{ }^{47}$
There is some evidence for the use of CYA in certain special populations. In KTR renal failure secondary to focal segmental glomerulosclerosis (FSGS), evidence suggests CYA may decrease FSGS recurrence post-transplant. ${ }^{48}$ In patients who develop posterior reversible encephalopathy syndrome (PRES) while taking IR-TAC, switching to CYA may be a reasonable alternative given alternative mechanisms of action for causing PRES. ${ }^{49}$

In summary, IR-TAC has replaced CYA as the preferred $\mathrm{CNI}$ post-transplant. However, in the setting of a drug shortage or unavailability, CYA may be used to prevent rejection following transplant. Practitioners should consider the differing ADE profile and counsel patients appropriately. Additionally, MMF dosing adjustments may be necessary when switching from IR-TAC to CYA to account for lower MPA AUC. Finally, special patient populations may benefit from utilization of CYA over alternative IR-TAC replacements, such as those experiencing neurotoxicity or NODAT and patients with a primary diagnosis of FSGS.

\subsection{Non-Calcineurin inhibitor alternatives}

When alternative CNIs are either not appropriate or not available for use in a particular patient, the clinician must turn to a non-CNI-based regimen. Overall, these regimens are plagued by higher incidence of BPAR than IR-TAC-based regimens; however, careful patient selection can improve successful outcomes. The following section summarizes the use of MTOR-Is, belatacept, and induction agents for $\mathrm{CNI}$ dose sparing or avoidance.

\subsection{1 | MTOR-Is (Sirolimus, Everolimus)}

Currently, two orally administered mammalian target of rapamycin inhibitors (mTORis), sirolimus (SRL) and everolimus (EVR), are available for the prophylaxis of organ rejection in adult transplant recipients. SRL was the first available, FDA-approved in 1999, with EVR following approximately ten years later in $2010 .^{50}$ Both agents inhibit protein synthesis and cell cycle progression via binding to rapamycin and the FK binding protein 12 (FKBP-12) and ultimately inhibiting IL-2-induced T-, NK, and B-cell proliferation. ${ }^{51}$ Although site of actions is similar, EVR has a shorter half-life, improved bioavailability, and lower average target blood trough concentrations (3-10 $\mathrm{ng} / \mathrm{mL}$ vs 4-15 $\mathrm{ng} / \mathrm{mL}$ ) compared to SRL. ${ }^{50,52}$

The mTORis differ from IR-TAC via their mechanisms of action, adverse event profiles, and the potential to have anti-proliferative effects, anti-angiogenic effects, anti-viral effects, and reduced nephrotoxicity. Commonly, mTORis are used in combination with other immunosuppressant agents either to increase cumulative drug exposure or to minimize toxicities.

Complete avoidance or withdrawal of CNI with mTORi substitution in KTRs has been extensively evaluated, including meta-analysis of multiple RCTs. ${ }^{53}$ In large, these studies demonstrate an increase in acute rejection with a reduction in malignancy and CMV, as well 
as some improvement in renal function. Death and graft loss are typically not different between groups, and neither type of CNI nor a steroid-free regimen appeared to influence outcomes. The de novo use of lower dose SRL (trough range $4-8 \mathrm{ng} / \mathrm{mL}$ ) in the setting of daclizumab induction in combination with MMF and prednisone has resulted in increased BPAR (37.2\% vs $12.3 \%$ in IR-TAC arm; $P<.001)$ and reduced allograft survival ( $89.3 \%$ vs $94.2 \%$ in IR-TAC arm) at 12 months. $^{42}$ The de novo use of SRL/MMF with higher trough ranges of $10-15 \mathrm{ng} / \mathrm{mL}$ in the immediate post-transplant period, however, has not resulted in increased BPAR or reduced allograft survival and is favorably associated with a $15-17 \mathrm{~mL} / \mathrm{min}$ higher eGFR compared to non-SRL/MMF comparator arms. ${ }^{54,55}$

Studies investigating conversion from CNI to mTORi in KTRs also demonstrate improvement in GFR; however, this benefit is often lost with late conversion. ${ }^{56}$ Conversion within 6 months post-transplant has been evaluated in 6 RCTs. ${ }^{57-62}$ The ZEUS and Spare-theNephron trials are most notable and evaluated CNI/MMF to mTORi/ MMF conversion in a large subset of patients. Both studies demonstrated a higher incidence of BPAR with mTORi/MMF use compared to $\mathrm{CNI} / \mathrm{MMF}$ (7.4\%-13.9\% vs $6 \%-7.5 \%$ ), but GFR was better in this group (72-75 $\mathrm{mL} / \mathrm{min}$ vs $61-71 \mathrm{~mL} / \mathrm{min}$ ).

The CONVERT trial stratified $830 \mathrm{KTRs}$ according to baseline GFR (20-40 mL/min or $>40 \mathrm{~mL} / \mathrm{min}$ ) and randomized to SRL/MMF or remain on $\mathrm{CNI} / \mathrm{MMF}$ at 6-120 months post-transplant. ${ }^{56}$ Patients with a baseline GFR $>40 \mathrm{~mL} / \mathrm{min}$ had a higher mean GFR after SRL conversion at all time points (24-month GFR 62.6 vs $59.9 \mathrm{~mL} / \mathrm{min}$; $P=.009)$. Graft and patient survival and BPAR were similar between groups. Enrollment in the GFR $20-40 \mathrm{~mL} / \mathrm{min}$ stratum was halted prematurely due to a higher incidence of the safety endpoint of the composite rate of the first occurrence of BPAR, graft loss, or death 12 months after randomization among the SRL-converted patients. Additionally, post hoc analyses revealed that the risk-benefit profile was most favorable in the baseline GFR $>40 \mathrm{~mL} / \mathrm{min}$ subgroup and those with a protein:creatinine ratio $(\mathrm{UPr} / \mathrm{Cr}) \leq 0.11$.

The TRANSFORM trial evaluated 2037 de novo renal transplant recipients in a prospective, open-label design. Patients were randomized 1:1 within 24 hours post-transplant to receive EVR (trough range 3-8 $\mathrm{ng} / \mathrm{mL}$ ) with reduced-exposure $\mathrm{CNI}$ or MMF with standard-exposure $\mathrm{CNI}^{63}$ The 24-month data were recently published and were consistent with the 12-month data demonstrating comparable efficacy between groups. ${ }^{64}$ The EVR and reduced-exposure $\mathrm{CNI}$ were non-inferior to standard-exposure $\mathrm{CNI}$ for the primary endpoint of treated BPAR or eGFR $<50 \mathrm{~mL} / \mathrm{min} / 1.73 \mathrm{~m}^{2}$. While the incidence of de novo donor-specific antibodies (12.3\% vs $17.6 \%$ ), CMV (2.8\% vs $13.5 \%)$, and BK virus infections (5.8\% vs $10.3 \%)$ was lower in the EVR and reduced-exposure $\mathrm{CNI}$ arm, discontinuation rates due to adverse events were higher ( $27.2 \%$ vs $15 \%$ ). This is the largest study to date that demonstrates the advantages of EVR with reduced-exposure $\mathrm{CNI}$ in de novo renal transplant recipients.

Conversion to mTORi with CNI withdrawal in LTRs has been investigated for kidney dysfunction, intolerance to $\mathrm{CNI}$, to delay hepatocellular carcinoma recurrence, and in the management of post-transplant malignancies. ${ }^{65-69}$ Efficacy is highly dependent on the time after liver transplant, concomitant immunosuppression, and use of induction therapy. Similar to KTR, data demonstrate an increased risk of rejection, but often an improvement in renal function, especially if conversion occurs early ( $\leq 6$ months post-transplant). Several studies investigated early use of mTORi with $\mathrm{CNI}$ withdrawal, ${ }^{66-69}$ and many demonstrated an increased risk of BPAR. This was confirmed in a meta-analysis including four RCTs, which associated early mTORi use with a 71\% increase in risk of BPAR (RR: 1.71; $95 \% \mathrm{Cl}: 1.15-2.53 ; P<.01) .{ }^{70}$ Despite this increase in rejection, eGFR improvements 12 months post-transplant range from 8 to $27 \mathrm{~mL} / \mathrm{min} / 1.73 \mathrm{~m}^{2}$ across studies. ${ }^{66,68,69}$

Data evaluating mTORi use with $\mathrm{CNI}$ avoidance or withdrawal post-heart transplant have shown similar outcomes to other organ groups: an increased risk of BPAR, improved renal function, reduced incidence of CMV, high discontinuation rates, and no difference in patient and allograft survival when compared to CNI/MMF regimens. ${ }^{71-73}$ The additional benefit of mTORi use post-cardiac transplant is its impact on coronary allograft vasculopathy (CAV). The SCHEDULE trial randomized de novo heart transplant recipients who received rabbit anti-thymocyte globulin (ATG) induction to EVR (trough 6-10 ng/mL) with reduced $\mathrm{CNI}$ followed by $\mathrm{CNI}$ withdrawal at weeks 7-11 or to a conventional $\mathrm{CNI}$-based regimen. ${ }^{74} \mathrm{At}$ the end of the 12-month trial, the EVR-treated patients had significantly better renal function and significantly lower incidence of CAV, but higher BPAR rates compared to the $\mathrm{CNI}$ cohort ( $73 \%$ vs $52 \%$; $P<.05)$. The 36-month data showed a GFR difference of $18.3 \mathrm{~mL} /$ min between groups and continued improvement in CAV; however, increased BPAR and high discontinuation rates were notable in the EVR cohort. ${ }^{73}$ The benefits of renal function and CAV post-heart transplant should be weighed with the risk of BPAR.

Data to support the efficacy of CNI withdrawal and mTORi conversion after lung transplantation are limited to single-center trials without CNI comparison. ${ }^{75,76}$ No detrimental effect on pulmonary function or outcomes has clearly been documented in the conversion setting, but comparative efficacy has not been evaluated. De novo use is not preferred given effects on anastomotic healing. ${ }^{77}$ Given the high incidence of acute and chronic rejection after lung transplantation, complete $\mathrm{CNI}$ withdrawal is generally not recommended. The same is true for $\mathrm{CNI}$ withdrawal with mTORi conversion after pancreas transplant. ${ }^{78}$

Recommendations regarding conversion from a CNI to an mTORi post-transplant vary by allograft type. The conversion from a CNI to an mTORi post-kidney transplant can be considered in the setting of adequate allograft function (GFR $>40 \mathrm{~mL} / \mathrm{min}$ ) and absence of proteinuria ( $\mathrm{UPr} / \mathrm{Cr} \leq 0.11$ ). Post-liver transplant, mTORi conversion can be associated with rejection, so adjunctive antimetabolite is advised. In addition, the transition to mTORi should be gradual and over an extended period of time when possible. High rejection rates following $\mathrm{CNI}$ to mTORi conversion post-heart transplant make conversion riskier; however, when no alternative exists, it can be done while optimizing trough levels in conjunction with MMF and corticosteroids. Finally, in lung and PTRs, mTORi therapy with complete CNI withdrawal is generally not recommended due to higher rejection risks. 
Additionally, if used post-lung transplant, endoscopic confirmation of anastomotic healing is necessary prior to conversion given the risk of poor airway healing and anastomotic dehiscence. ${ }^{77}$ Outside of KTRs, in which mTORis have been used de novo or for early conversion, initiation of mTORi is typically not recommended until after 30 days post-transplant due to impaired wound healing and anastomotic dehiscence.

Therapeutic drug monitoring of mTORis is recommended for all patients to ensure efficacy and safety. Therapeutic optimization may be delayed when drug-level analysis occurs via send-out laboratories as obtaining results may be postponed. Additionally, given the long $\mathrm{t} 1 / 2$ of mTORis vs CNIs, therapeutic drug monitoring and dose titration should be done at a slower rate than typically used for IR-TAC.

Common ADEs include hyperlipidemia, edema, leukopenia, anemia, stomatitis, proteinuria, and wound healing complications (including wound dehiscence, incisional hernia, lymphocele). ADEs can generally be managed with close monitoring and follow-up, and many are manageable with adjuvant treatment or reversible upon discontinuation of mTORi. More significant and severe ADEs include an increased risk of thromboembolism and interstitial pneumonitis. An important consideration of mTORi is that the ADE-related dropout rate in clinical trials is $20 \%-40 \% .{ }^{79}$ Additionally, no generic formulation is currently available for EVR, so this agent may be cost prohibitive for certain patients.

In summary, the use of mTORi-based regimens devoid of CNIs has demonstrated efficacy. However, careful consideration is required related to patient population, time post-transplant, concomitant immunosuppression, potential for rejection, and ADE profile to ensure safety. For all organ types, mTORis should be used in conjunction with adjunctive therapies (ie MMF and corticosteroids) to minimize risk of rejection. Trough mTORi levels should be optimized, and the transition to mTORi should be gradual and over an extended period of time when possible. Utilization as part of a CNI dose-sparing regimen could also be pursued. The frequency of post-transplant follow-up and clinical assessments should be amplified, and persistent vigilance to diagnose and manage therapy-related toxicities is required to ensure optimal outcomes.

\subsection{2 | Belatacept}

In 2011, a novel immunosuppressive agent, belatacept, administered via monthly intravenous infusion, was FDA-approved for use in KTRs. Belatacept exerts its effect via binding to CD80 and CD86 ligands on antigen-presenting cells, thereby blocking CD28-mediated co-stimulation of T lymphocytes. ${ }^{80}$ Belatacept was approved following two randomized, multicenter non-inferiority trials that compared belatacept-based regimens to CYA. ${ }^{81,82}$ The dosing and administration schedule of belatacept varies, depending on indication. De novo dosing is $10 \mathrm{mg} / \mathrm{kg} \mathrm{IV}$ postoperative day 1 , day 5 , week 2 , week 4 , week 8 , and week 12 , followed by a maintenance dose of $5 \mathrm{mg} / \mathrm{kg}$ every 4 weeks. ${ }^{80}$ Currently, an FDA-approved dosing scheme for late conversion does not exist but studies suggest $5 \mathrm{mg} / \mathrm{kg}$ on days
$1,15,29,43$, and 57 followed by maintenance of $5 \mathrm{mg} / \mathrm{kg}$ every 4 weeks. $^{83,84}$

Unlike IR-TAC, belatacept has a standard, weight-based dosing that does not require therapeutic drug monitoring. Belatacept is devoid of many of the common side effects of IR-TAC, including hypertension, hyperlipidemia, neurotoxicity, and nephrotoxicity. ${ }^{80}$ Evidence supports improved GFR with regimens containing belatacept as compared to IR-TAC. ${ }^{85-87}$ Given monthly maintenance dosing, adherence has been proposed as an added benefit of belatacept. Despite these benefits, belatacept can cause an early increase in proteinuria, the clinical significance of which is unknown and is associated with an increased risk of rejection. ${ }^{81,85-88}$ Additionally, belatacept was associated with a significant increase in post-transplant lymphoproliferative disease (PTLD) in the drug trials, and therefore, administration is contraindicated in patients who are EBV IgGnegative, due to a theoretical increased risk of PTLD in the setting of primary EBV infection. ${ }^{80}$

Studies directly comparing outcomes between de novo IR-TAC and belatacept immediately following transplantation have been limited to KTRs. ${ }^{85-87}$ A small, prospective, RCT of adult KTR who received basiliximab induction found a higher incidence of rejection in the belatacept compared to the IR-TAC arm ( $55 \%$ vs $10 \% ; P=.006) .{ }^{85}$ Similar results were seen in a propensity-matched cohort of adult KTR discharged on belatacept-based versus TAC-based regimens. ${ }^{86}$ Incidence of acute rejection was higher in the belatacept compared to the IR-TAC group (odds ratio, 3.12; 95\% Cl, 2.13-4.57); there was no difference in mortality or graft loss risk. One-year post-transplant eGFR was significantly lower among IR-TAC compared to belatacept-treated patients (median eGFR $58.5 \mathrm{~mL} / \mathrm{min} / 1.73 \mathrm{~m}$ vs eGFR $\left.62.3 \mathrm{~mL} / \mathrm{min} / 1.73 \mathrm{~m}^{2}\right) .{ }^{86}$ Consistent with the above studies, Wen and colleagues found belatacept was associated with a higher risk of 1-year acute rejection compared to IR-TAC, with highest rates associated with non-lymphocyte-depleting induction (aHR 2.65, 95\% $\mathrm{Cl}$ 1.90-3.70). eGFR was higher with belatacept plus IR-TAC and belatacept alone versus IR-TAC alone (mean eGFR 65.6, 60.4, and $\left.54.3 \mathrm{~mL} / \mathrm{min} / 1.73 \mathrm{~m}^{2}\right) .{ }^{87}$ Lastly, Ferguson and colleagues compared outcomes of three cohorts following ATG induction and early steroid withdrawal: belatacept-MMF, belatacept-SRL, or TAC-MMF. ${ }^{88}$ The belatacept arm had more BPAR than the other arms (4:1:1), but was associated with a higher eGFR (by $8-10 \mathrm{~mL} / \mathrm{min}$ ) than the IR-TAC group; overall safety was comparable between groups.

In patients with ongoing delayed graft function (DGF), intolerance to IR-TAC or evidence of IR-TAC toxicity, conversion to belatacept may be considered. Conversion of KTRs from IR-TAC to belatacept has been studied in both the early ( $<6$ months) and the late (>6 months) post-transplant periods. Nair and colleagues found that early conversion of patients with delayed or poor graft function from IR-TAC to belatacept was both safe and efficacious. ${ }^{83}$ Additionally, studies have suggested that it can improve kidney function, particularly for patients experiencing prolonged DGF. ${ }^{89}$ Late conversion of KTRs from IR-TAC to belatacept has also been shown to improve renal function at the time of conversion, although this improvement is not always maintained long term. ${ }^{90}$ 
Off-label use in lung, pancreas, and heart transplant recipients has been documented but is limited to individual case reports where regimen varied widely. ${ }^{91-93}$ Most individuals in these studies were converted to belatacept due to non-adherence or CNI toxicity. Although data are minimal, there may be situations in which belatacept may be considered. Additional studies are needed to fully elucidate the role of belatacept in these populations.

Belatacept in LTRs is not routinely recommended due to an increased risk of graft loss and death. ${ }^{80,94}$ However, some centers continue to explore its use to avoid ADEs of CNIs and improve adherence. A study by LaMattina and colleagues provides evidence that belatacept use may be beneficial in select patients. ${ }^{95}$ At this time, it is recommended to avoid use after liver transplant, although it may be considered as a last line option.

Belatacept use is further complicated due to the manufacturer's limited distribution. Clinicians must enroll patients in the Nulojix Distribution Program http://www.nulojixhcp.bmscustomerconnect. $\mathrm{com} /$ servlet/servlet.FileDownload?file=00Pi000000nzpG5EAI) to obtain approval for use and a patient identification number (PIN) prior to administration. It is difficult to compare the cost of belatacept and IR-TAC due to multiple variables. Insurance approval should be obtained prior to initiating therapy and may be challenging in non-KTRs given lack of data.

In summary, while belatacept is considered a non-inferior alternative to IR-TAC in KTRs, belatacept-treated patients are more likely to experience acute rejection. However, despite increased early rejection, patients experience a higher eGFR at 1 year than their TACtreated counterparts. Belatacept has been explored in non-KTRs, but data are limited and the inability to obtain insurance approval may significantly limit access. Belatacept is not recommended for routine use in LTRs given poor outcomes in initial manufacturer studies, although it may be considered in rare cases.

\section{3 | Induction agents for maintenance}

In SOT, maintenance immunosuppression involves the use of multiple agents in combination to prevent allograft rejection. Alternatively, induction immunosuppressants such as lymphocyte-depleting agents [ATG and alemtuzumab] and interleukin 2 receptor antagonists (IL2RAs) [daclizumab and basiliximab] are classically given at the time of transplant surgery to prevent acute rejection during this highly inflammatory period of initial immune activation. Literature exists that describes induction immunosuppressants as part of the maintenance regimen and in rare circumstances may be necessary.

\subsection{1 | Non-lymphocyte-depleting agents (daclizumab, basiliximab)}

The IL2RAs are non-depleting induction agents that block CD-25, the T-cell IL-2 receptor, to prevent proliferation of T cells. ${ }^{96}$ IL2RAs include daclizumab, a humanized monoclonal antibody (discontinued in 2009), and basiliximab, a chimerized monoclonal antibody. Drug effects last approximately 1-2 months. ${ }^{97}$ In LTRs, IL2RA induction allows delays in $\mathrm{CNI}$ initiation, minimizing $\mathrm{CNI}$ exposure and reducing nephrotoxicity risk. ${ }^{98-100}$ While literature is limited to case reports and small case series, this technique has been extrapolated to heart, pancreas, and KTRs for patients intolerant to CNIs. ${ }^{101-104}$ Regimens range from weekly to monthly IL2RA therapy. One of the first reports of IL2RA maintenance immunosuppression described a mixed allograft population of 11 heart, liver, and combined heart-kidney transplant recipients initiated on an IL2RA for a "CNI-holiday." Basiliximab 20 mg every 20 days or daclizumab $1.5 \mathrm{mg} / \mathrm{kg}$ weekly was given until $\mathrm{CNI}$ re-initiation. In this series, patients were maintained on IL2RAs for a mean of 52 days (range 6-210 days). Patients otherwise received combinations of mTORi, MMF, and corticosteroids for maintenance. This study demonstrated that IL2RAs can be given to allow resolution of acute renal injury without incidence of rejection or adverse effect. ${ }^{101}$ An additional publication described 2 cases of de novo IL2RA therapy after KTR, both patients achieving successful patient and graft outcomes with a triple-drug regimen of MMF, steroids, and monthly basiliximab at doses of $20-40 \mathrm{mg}$ for over 3 years post-transplant. ${ }^{104}$ This technique has also been studied in PTRs, who are considered higher immunologic risk. In a retrospective analysis of 25 PTRs, a maintenance regimen of monthly daclizumab (1-2 mg/kg) with either MPA or SRL improved graft survival and reduced immunologic loss rate at 1,3 , and 5 years when compared to a matched control. ${ }^{103}$ While the maintenance regimens in the controls were not specified, both groups were steroid-sparing.

Unfortunately, studies demonstrate unacceptably high rates of rejection when studied on a larger scale without continuation of CNIs. In a study of approximately 100 de novo KTRs, CNI therapy was replaced with daclizumab $1 \mathrm{mg} / \mathrm{kg}$ every 2 weeks for a total of five doses. At 1 year, early rejection rates were $45 \%$ requiring $\mathrm{CNI}$ reintroduction in $>90 \%$ of cases. ${ }^{102}$ Therefore, ongoing therapy must be ensured.

IL2RAs represent an attractive option for $\mathrm{CNI}$ replacement due to non-depleting mechanism of action, long drug half-life, and limited ADEs. Many studies have evaluated the use of daclizumab, which is no longer available, and has different pharmacokinetics than basiliximab. Additionally, no head-to-head comparisons with belatacept exist, which largely fills this role at a similar cost, and substantiated by robust clinical data.

\subsection{2 | Lymphocyte-depleting agents (rabbit anti- thymocyte globulin (rATG), alemtuzumab)}

Lymphocyte-depleting agents induce cell lysis, thereby reducing circulating lymphoid cell lines. ${ }^{105}$ Immune reconstitution can take a year, although effects may be more prolonged. ${ }^{105}$ Due to the profound release of cytokines from cellular destruction and the protracted depletion of cellular lines, ATG and alemtuzumab are less tolerable and carry a higher risk for ADEs including infection and malignancy compared to the typical maintenance agents. 
To our knowledge, no study describes the use of a ATG, a polyclonal antihuman thymocyte immunoglobulin, derived from rabbits and resulting in reduction of multiple lymphoid cell lines, but predominantly CD3+ T cells, in a maintenance regimen. ${ }^{106}$ Theoretically, given its animal derivation, subsequent courses of rATG could be less efficacious due to immune sensitization to animal protein content. However, while antibodies to rATG have been detected in vitro, the creation of anti-rATG antibodies has not had a clinically significant impact on rejection treatment. ${ }^{107,108}$ However, this concern in addition to safety concerns with continued ongoing dosing likely explains the lack of the use of a polyclonal product in maintenance regimens.

Alemtuzumab is a humanized monoclonal antibody targeting the CD52 antigen widely expressed on lymphocytes, macrophages, monocytes, and eosinophils, which results in prolonged and profound depletion of T- and B-cell lines with CD4+ suppression for years after administration. ${ }^{109} \mathrm{~A}$ single study describes the use of alemtuzumab in a maintenance regimen. ${ }^{110}$ In this prospective observational cohort study of 75 PTRs (43\% PTA, 23\% PAK, and $27 \%$ SPK), there were no differences in patient and graft survival rates at 6 months when patients received a regimen consisting of $120 \mathrm{mg}$ alemtuzumab (30 mg POD 0, 2, 14 and 42) and a single dose of $1.25 \mathrm{mg} / \mathrm{kg}$ rATG on POD4 in combination with MMF $\geq 2 \mathrm{~g} / \mathrm{d}$. Additional doses of alemtuzumab were given if absolute lymphocyte counts were $\geq 200 / \mathrm{mm}^{3}$. Patients could receive a max of 10 doses of alemtuzumab in the first year. This regimen was compared to 266 standard of care patients that received rATG induction and IR-TAC maintenance. If MMF was dosed $<2 \mathrm{~g} / \mathrm{d}$ due to intolerance, the regimen could be modified by switching MMF to SRL or adding daclizumab $1 \mathrm{mg} / \mathrm{kg}$ every other month (IL2RA maintenance). Steroid use and MMF dose in the control group were not specified. There were no differences in patient and graft survival rates in the 6-month follow-up; however, incidence of rejection was significantly higher in the study group. Risk of intraabdominal infection, cytomegalovirus infection, and PTLD were not different between groups; however, patients in the study group were maintained on 12 months of valganciclovir.

In summary, the use of depleting induction as part of the maintenance regimen is atypical and increases the risk for immediate intolerance and long-term infectious and malignant complications. Overall, monoclonal antibodies have been studied in this manner, primarily IL2RAs, but data are limited. Overall, data suggest an increased risk of rejection compared to CNIs, particularly in the setting of $\mathrm{CNI}$ discontinuation. If the use of an induction agent in the maintenance regimen is desired due to lack of other viable options, careful patient selection is required along with intensified infectious prophylaxis to ensure positive patient and allograft outcomes.

\section{3 | CONCLUSION}

Our review of available literature investigating the efficacy and safety of IR-TAC alternatives demonstrates that all non-TACbased regimens are plagued with an increased risk of BPAR, but overall improved tolerance particularly related to nephrotoxicity. No difference in BPAR exists between ER-TAC formulations and IR-TAC, the majority of data with KTRs and LTRs. LCPT may be preferred in patients with TAC-associated, or a higher propensity for, neurotoxicity due to the achievement of lower peak concentrations. Overall, mTORis are associated with higher rates of BPAR and discontinuation due to ADEs in kidney, liver, and heart transplant recipients, but appear to be associated with reduction in opportunistic viral infection and malignancy. Careful patient selection and monitoring are recommended when converting IR-TAC to mTORi. Belatacept is an attractive alternative for KTRs experiencing nephrotoxicity or non-adherence and has demonstrated positive long-term outcomes. However, no robust data supporting the use of belatacept in non-KTR populations exist, making it difficult to obtain insurance coverage. Belatacept is also associated with higher rates of rejection. While data exist describing the use of classical induction agents for maintenance, data are limited to small case series and special populations. IL2RAs are preferred over depleting agents overall; however, belatacept largely fills this role with better data, particularly in KTRs. This review confirms that tacrolimus is the gold standard with superior outcomes and demonstrates that in times of limited IR-TAC availability transplant clinicians should carefully evaluate unique patient modifiers to ensure the best alternative immunosuppressant regimen is selected.

\section{CONFLICT OF INTERESTS}

None.

\section{AUTHOR CONTRIBUTIONS}

All authors contributed to concept/design, analysis/interpretation, drafting article, critical revision, and final approval of the article.

\section{ORCID}

Margaret R. Jorgenson (iD https://orcid.org/0000-0001-6088-9727 Jillian L. Descourouez (D) https://orcid.org/0000-0002-1196-5110 Melissa R. Laub iD https://orcid.org/0000-0002-6251-9153

\section{REFERENCES}

1. Webster AC, Woodroffe RC, Taylor RS, Chapman JR, Craig JC. Tacrolimus versus ciclosporin as primary immunosuppression for kidney transplant recipients: meta-analysis and meta-regression of randomised trial data. BMJ. 2005;331(7520):810-821.

2. Muduma G, Saunders R, Odeyemi I, Pollock RF. Systematic review and meta-analysis of tacrolimus versus ciclosporin as primary immunosuppression after liver transplant. PLoS One. 2016;11(11):e0160421.

3. FDA. Drug shortages. 2019. Accessed at https://www.accessdata. fda.gov/scripts/drugshortages/default.cfm. Accessed September 19, 2019

4. Astagraf $\mathrm{XL}^{\circledR}$ [package insert]. Northbrook, IL: Astellas Pharma US Inc.; 2015.

5. Envarsus $X R^{\circledR}$ [package insert]. Edison, NJ: Veloxis Pharmaceuticals, Inc; 2018.

6. Philosophe B, Leca N, West-Thielke PM, et al. Evaluation of flexible tacrolimus drug concentration monitoring approach in patients 
receiving extended-release once-daily tacrolimus tablets. J Clin Pharmacol. 2018;58(7):891-896.

7. Tremblay S, Nigro V, Weinberg J, Woodle ES, Alloway RR. A steady-state head-to-head pharmacokinetic comparison of All FK-506 (Tacrolimus) formulations (ASTCOFF): an open-label, prospective, randomized, two-Arm, three-period crossover study. Am J Transplant. 2017;17:432-442.

8. Staatz CE, Tett SE. Clinical pharmacokinetics of once-daily tacrolimus in solid-organ transplant patients. Clin Pharmacokinet. 2015;54:993-1025.

9. Asempa TE, Rebellato LM, Hudson S, Briley K, Maldonado AQ. Impact of CYP3A5 genomic variances on clinical outcomes among African American kidney transplant recipients. Clin Transplant. 2018;32(1):e13162.

10. Trofe-Clark J, Brennan DC, West-Thielke P, et al. Results of ASERTAA, a randomized prospective crossover pharmacogenetic study of immediate release tacrolimus versus extended release tacrolimus in African American kidney transplant recipients. Am J Kidney Dis. 2018;71:315-326.

11. Huppertz A, Ott C, Bruckner T, et al. Prolonged-release tacrolimus is less susceptible to interaction with the strong CYP3A inhibitor voriconazole in healthy volunteers. Clin Pharmacol Ther. 2019;106:1290-1298.

12. Langone A, Steinberg SM, Gedaly R, et al. Switching study of kidney transplant patients with tremor to LCP-Tacro (STRATO): an open-label, multicenter, prospective phase $3 \mathrm{~b}$ study. Clin Transplant. 2015;29:796-805.

13. ClinicalTrials.gov [Internet]. Bethesda (MD): National Library of Medicine (US). 2000. Identifier: NCT03762473, Conversion to Envarsus Post Kidney Transplant Protects Against BK Infection. Available from: https://clinicaltrials.gov/ct2/show/NCT03 762473

14. Shuker N, Cadogan M, van Gelder $T$, et al. Conversion from twice-daily to once-daily tacrolimus does not reduce intrapatient variability in tacrolimus exposure. Ther Drug Monit. 2015;37(2):262-269.

15. Alloway R, Steinberg S, Khalil K, et al. Two years postconversion from a prograf-based regimen to a once-daily tacrolimus extended-release formulation in stable kidney transplant recipients. Transplantation. 2007;83(12):1648-1651.

16. Silva HT Jr, Yang HC, Meier-Kriesche HU, et al. Long-term follow-up of a phase III clinical trial comparing tacrolimus extended-release/ MMF, tacrolimus/MMF, and cyclosporine/MMF in de novo kidney transplant recipients. Transplantation. 2014;97(6):636-641.

17. Saengram W, Vadcharavivad S, Poolsup N, Chancharoenthana W. Extended release versus immediate release tacrolimus in kidney transplant recipients: a systematic review and meta-analysis. Eur $J$ Clin Pharmacol. 2018;74(10):1249-1260.

18. Dib M, Barbas A, Marquez M, et al. Safety and efficacy of conversion from conventional twice daily tacrolimus to once daily extended release tacrolimus in stable pancreas transplant (SPK and PAK) recipients [abstract]. Am J Transplant. 2015;15. Special Issue: SI, Meeting Abstract: 889

19. Trunečka $P$, Boillot $O$, Seehofer $D$, et al. Once-daily prolonged-release tacrolimus (ADVAGRAF) versus twice-daily tacrolimus (PROGRAF) in liver transplantation. Am J Transplant. 2010;10(10):2313-2323.

20. González-Vílchez F, Crespo-Leiro M, Palomo J, et al. Multicentre study to evaluate conversion from standard-release tacrolimus (SRT) to extended-release tacrolimus (ERT) in a large series of heart transplanted patients. J Heart Lung Transplant. 2015;34(4):S32.

21. Gonzalez-Vilchez F, Lambert J, Almenar L, et al. A comparison of the extended-release and standard-release formulations of tacrolimus in de novo heart transplant recipients: a 12-month outcome Study. J Heart Lung Transplant. 2014;33(4):S172.
22. González-Vílchez F, Lambert JL, et al. Efficacy and safety of de novo and early use of extended-release tacrolimus in heart transplantation. Rev Esp Cardiol (Engl Ed). 2018;71(1):18-25.

23. Méndez A, Berastegui C, López-Meseguer M, etal. Pharmacokinetic study of conversion from tacrolimus twice-daily to tacrolimus once-daily in stable lung transplantation. Transplantation. 2014;97(3):358-362.

24. Soto GAC, Ruiz-Antoran B, Laporta R, et al. Dose increase needed in most cystic fibrosis lung transplantation patients when changing from twice- to once-daily tacrolimus oral administration. Eur J Clin Pharmacol. 2015;71(6):715-722.

25. Etienne I, Woillard JB, Marquet P, Estenne M, Knoop C, Monchaud C. The once-daily tacrolimus extended-release formulation provides similar drug exposure in non-CF and CF lung transplant recipients when compared to the conventional twice-daily formulation. J Cyst Fibros. 2014;13(2):S107.

26. Budde K, Bunnapradist S, Grinyo JM, et al. Novel once-daily extended-release tacrolimus (LCPT) versus twice-daily tacrolimus in de novo kidney transplants: one-year results of phase III, double-blind, randomized trial. Am J Transplant. 2014;14:2796-2806

27. Rostaing L, Bunnapradist S, Grinyó JM, et al. Novel once-daily extended release tacrolimus (LCPT) versus twice-daily tacrolimus in de novo kidney transplants: two- year results of phase 3, doubleblind, randomized trial. Am J Kidney Dis. 2016;67:648-659.

28. Bunnapradist S, Ciechanowski K, West-Thielke P, et al. Conversion from twice-daily tacrolimus to once-daily extended release tacrolimus (LCPT): the phase III randomized MELT trial. Am J Transplant. 2013;13(3):760-769.

29. Bunnapradist S, Rostaing L, Alloway RR, et al. LCPT once-daily extended-release tacrolimus tablets versus twice-daily capsules: a pooled analysis of two phase 3 trials in important de novo and stable kidney transplant recipient subgroups. Transpl Int. 2016;29:603-611.

30. Alloway RR, Eckhoff DE, Washburn WK, Teperman LW. Conversion from twice daily tacrolimus capsules to once daily extended-release tacrolimus (LCP-Tacro): phase 2 trial of stable liver transplant recipients. Liver Transpl. 2014;20(5):564-575.

31. Altieri M, Delava G, Kimmoun E, Allaire M, Salamé E, Dumortier J. Conversion from once-daily prolonged-release tacrolimus to once-daily extended-release tacrolimus in stable liver transplant recipients. Exp Clin Transplant. 2018;3:321-325.

32. DuBay DA, Teperman L, Ueda K, et al. Pharmacokinetics of oncedaily extended-release tacrolimus tablets versus twice-daily capsules in de novo liver transplant. Clin Pharmacol Drug Dev. 2019;8(8):995-1008.

33. Kerstenetzky L, Descourouez JL, Jorgenson MR, et al. A single-center experience with tacrolimus LCP (Envarsus XR) in pancreas transplant recipients. Ann Pharmacother. 2018;52(4):392-396.

34. Sintes H, Sáez-Giménez B, Berastegui C, et al. Pharmacokinetic study of conversion between 2 formulations of once-daily extended-release tacrolimus in stable lung transplant patients. Transplantation. 2018;102:e439-e446.

35. ClinicalTrials.gov [Internet]. Bethesda (MD): National Library of Medicine (US). 2000. Identifier: NCT03373227. Phase II Study Evaluating the Efficacy of Tacrolimus Extended Release Tablets to Twice Daily Tacrolimus Dosing Regimen (Veloxis) 2017 Dec 14. Available from: https://clinicaltrials.gov/ct2/show/NCT03 373227

36. Glander P, Waiser J, Kasbohm S, et al. Bioavailability and costs of once-daily and twice-daily tacrolimus formulations in de novo kidney transplantation. Clin Transplant. 2018;32:e13311.

37. Dösch $\mathrm{A}$, Müller $\mathrm{S}$, Konstandin $\mathrm{M}$, et al. Compliance under modified release tacrolimus in chronic stable patients after heart transplantation. Transplantation. 2010;90(S2):3015. 
38. Oh CK, Bang JB, Kim SJ, et al. Improvement of medication adherence with simplified once-daily immunosuppressive regimen in stable kidney transplant recipients: A prospective cohort study. Asian J Surg. 2019;43(6):660-667. https://doi.org/10.1016/j.asjsur.2019.07.011

39. Hariharan S, Johnson CP, Bresnahan BA, Taranto SE, Mclntosh MJ, Stablein D. Improved graft survival after renal transplantation in the United States, 1988 to 1996. N Engl J Med. 2000;342(9):605-612.

40. Kidney Disease: Improving global outcomes (KDIGO) Transplant Work Group. KDIGO clinical practice guideline for the care of kidney transplant recipients. Am J Transplant. 2009;9(Suppl 3):S1-S155.

41. Kramer BK, Del Castillo D, Margreiter R, et al. Efficacy and safety of tacrolimus compared with ciclosporin $\mathrm{A}$ in renal transplantation: three-year observational results. Nephrol Dial Transplant. 2008;23:2386-2392.

42. Ekberg H, Tedesco-Silva H, Demirbas A, et al. Reduced exposure to calcineurin inhibitors in renal transplantation. N Engl J Med. 2007;357:2562-2575.

43. Saudek F, Malaise J, Boucek P, Adamec M, Euro-SPK Study Group. Efficacy and safety of tacrolimus compared with cyclosporin microemulsion in primary SPK transplantation: 3-year results of the EuroSPK 001 trial. Nephrol Dial Transplant. 2005;20(Suppl 2):ii3-ii10, ii62.

44. Ye F, Ying-Bin X, Yu-Guo W, Hetzer R. Tacrolimus versus cyclosporine microemulsion for heart transplant recipients: a meta-analysis. J Heart Lung Transplant. 2009;28(1):58-66.

45. Fan Y, Xiao YB, Weng YG. Tacrolimus versus cyclosporine for adult lung transplant recipients: a meta-analysis. Transplant Proc. 2009;41(5):1821-1824.

46. Hesselink DA, van Hest RM, Mathot RAA, et al. Cyclosporine interacts with mycophenolic acid by inhibiting the multidrug resistance-associated protein 2. Am J Transplant. 2005;5(5):987-994.

47. Grinyó JM, Ekberg H, Mamelok RD, et al. The pharmacokinetics of mycophenolate mofetil in renal transplant recipients receiving standard-dose or low-dose cyclosporine, low-dose tacrolimus or low-dose sirolimus: the Symphony pharmacokinetic substudy. Nephrol Dial Transplant. 2009;24(7):2269-2276.

48. Hirano T, Akashi T, Keira T, et al. Clinical impact of cyclosporine cellular pharmacodynamics in minimal change nephrotic syndrome. Clin Pharmacol Ther. 2000;68:532-540.

49. Senzolo M, Ferronato C, Burra P. Neurologic complications after solid organ transplantation. Transpl int. 2009;22:269-278.

50. Morath C, Arns W, Schwenger V, et al. Sirolimus in renal transplantation. Nephrol Dial Transplant. 2007;22(Suppl 8):viii61-viii65.

51. Rapamune [package insert]. Philadelphia, PA: Wyeth Pharmaceuticals LLC; 2019.

52. Zortress [package insert]. East Hanover, NJ: Novartis Pharmaceuticals Corporation; 2018.

53. Karpe KM, Talaulikar GS, Walters GD. Calcineurin inhibitor withdrawal or tapering for kidney transplant recipients. Cochrane Database of Syst Rev. 2017;(7):CD006750.

54. Flechner SM, Kurian SM, Solez K, et al. De novo kidney transplantation without use of calcineurin inhibitors preserves renal structure and function at two years. Am J Transplant. 2004;4(1776-1785):15.

55. Hamdy AF, El-Agroudy AE, Bakr MA, et al. Comparison of sirolimus with low-dose tacrolimus versus sirolimus-based calcineurin inhibitor-free regimen in live donor renal transplantation. Am J Transplant. 2005;5(2531-2538):16.

56. Schena FP, Pascoe MD, Alberu J, et al. Conversion from calcineurin inhibitors to sirolimus maintenance therapy in renal allograft recipients: 24-month efficacy and safety results from the CONVERT trial. Transplantation. 2009;87:233-242.

57. Budde K, Becker T, Arns W, et al. Everolimus-based, calcineurin-inhibitor-free regimen in recipients of de-novo kidney transplants: an open-label, randomised, controlled trial. Lancet. 2011;377:837-847.
58. Mjörnstedt L, Schwartz Sørensen S, von zur Mühlen B, et al. Renal function three years after early conversion from a calcineurin inhibitor to everolimus: results from a randomized trial in kidney transplantation. Transpl Int. 2015;28(42-51):25.

59. Lebranchu $Y$, ThierryA, Toupance $O$, et al. Efficacy on renal function of early conversion from cyclosporine to sirolimus 3 months after renal transplantation: Concept study. Am J Transplant. 2009;9:1115-1123.

60. Weir MR, Mulgaonkar S, Chan L, et al. Mycophenolate mofetil-based immunosuppression with sirolimus in renal transplantation: a randomized, controlled Spare-the-Nephron trial. Kidney Int. 2011;79:897-907.

61. Guba M, Pratschke J, Hugo C, et al. Renal function, efficacy, and safety of sirolimus and mycophenolate mofetil after short-term calcineurin inhibitor-based quadruple therapy in de novo renal transplant patients: one-year analysis of a randomized multicenter trial. Transplantation. 2010;90(2):175-183.

62. Heilman RL, Younan K, Wadei HM, et al. Results of a prospective randomized trial of sirolimus conversion in kidney transplant recipients on early corticosteroid withdrawal. Transplantation. 2011;92:767-773.

63. Pascual J, Berger SP, Witzke O, et al. Everolimus with reduced calcineurin inhibitor exposure in renal transplantation. J Am Soc Nephrol. 2018;29(7):1979-1991.

64. Berger SP, Sommerer C, Witzke O, et al. Two-year outcomes in de novo renal transplant recipients receiving everolimus-facilitated calcineurin inhibitor reduction regimen from the TRANSFORM study. Am J Transplant. 2019;19(11):3018-3034.

65. De Simone P, Nevens F, De Carlis L, et al. Everolimus with reduced tacrolimus improves renal function in de novo liver transplant recipients: a randomized controlled trial. Am J Transplant. 2012;12(11):3008-3020.

66. Teperman L, Moonka D, Sebastian A, et al. Calcineurin inhibitor-free mycophenolate mofetil/sirolimus maintenance in liver transplantation: the randomized spare-the-nephron trial. Liver Transpl. 2013;19(7):675-689.

67. Glover TE, Watson CJE, Gibbs P, et al. Conversion from calcineurin to mammalian target of rapamycin inhibitors in liver transplantation: a meta-analysis of randomized controlled trials. Transplantation. 2016;100(3):621-629.

68. Saliba F, Duvoux C, Dharancy S. Impact on renal function of stepwise withdrawal of tacrolimus combined with everolimus and ECMPS vs standard treatment combining tacrolimus and EC-MPS in de novo liver transplant recipients: results of the SIMCER Study. Am J Transplant. 2016;16:263.

69. Fischer L, Klempnauer J, Beckebaum S, et al. A randomized, controlled study to assess the conversion from calcineurin-inhibitors to everolimus after liver transplantation-PROTECT. Am J Transplant. 2012;12(7):1855-1865.

70. Tang C-Y, Shen Al, Wei X-F, et al. Everolimus in de novo liver transplant recipients: a systematic review. Hepatobiliary Pancreat Dis Int. 2015;14(5):461-469.

71. Zuckermann A, Keogh A, Crespo-Leiro MG, et al. Randomized controlled trial of sirolimus conversion in cardiac transplant recipients with renal insufficiency. Am. J. Transplant. 2012;12:2487-2497.

72. Groetzner J, Kaczmarek I, Schulz U, et al. Mycophenolate and sirolimus as calcineurin inhibitor-free immunosuppression improves renal function better than calcineurin inhibitor-reduction in late cardiac transplant recipients with chronic renal failure. Transplantation. 2009;87:726-733.

73. Andreassen AK, Andersson B, Gustafsson F, et al. Everolimus initiation with early calcineurin inhibitor withdrawal in de novo heart transplant recipients: three-year results from the randomized schedule study. Am. J. Transplant. 2016;16:1238-1247.

74. Andreassen AK, Andersson B, Gustafsson F, et al. Everolimus initiation and early calcineurin inhibitor withdrawal in heart transplant recipients: A randomized trial. Am J Transplant. 2014;14:1828-1838. 
75. Groetzner J, Wittwer T, Kaczmarek I, et al. Conversion to sirolimus and mycophenolate can attenuate the progression of bronchiolitis obliterans syndrome and improves renal function after lung transplantation. Transplantation. 2006;81(3):355-360.

76. Lischke R, Simonek J, Matousovic K, et al. Initial single-center experience with sirolimus after lung transplantation. Transplant Proc. 2006;38(9):3006-3011.

77. King-Biggs MB, Dunitz JM, Park SJ, et al. Airway anastomotic dehiscence associated with use of sirolimus immediately after lung transplantation. Transplantation. 2003;75(9):1437-1443.

78. Matias P, Araujo MR, Romão JE Jr, Abensur H, Noronha IL. Conversion to sirolimus in kidney-pancreas and pancreas transplantation. Transplant Proc. 2008;40(10):3601-3605.

79. Rostaing L, Kamar N. mTOR inhibitor/proliferation signal inhibitors: entering or leaving the field? J Nephrol. 2010;23:133-142.

80. Belatacept [package insert].Princeton, NJ: Bristol-Myers Squibb Company; 2019.

81. Vincenti F, Charpentier B, Vanrenterghem Y, et al. A phase III study of belatacept-based immunosuppression regimens versus cyclosporine in renal transplant recipients (BENEFIT study). Am J Transplant. 2010;10:535-546.

82. Pestana JOM, Grinyo JM, Vanrenterghem Y, et al. Three-year outcomes from BENEFIT-EXT: a phase III study of belatacept versus cyclosporine in recipients of extended criteria donor kidneys. Am J Transplant. 2012;12:630-639.

83. Nair V, Liriano-Ward L, Kent R, et al. Early conversion to belatacept after renal transplantation. Clin Transplant. 2017;31(5):e12951.

84. Grinyó JM, Del Carmen RM, Alberu J, et al. Safety and efficacy outcomes 3 years after switching to belatacept from a calcineurin inhibitor in kidney transplant recipients: results from a phase 2 randomized trial. Am J Kidney Dis. 2016;69(5):587-594.

85. de Graav GN, Baan CC, Clahsen-van Groningen MC, et al. A randomized controlled clinical trial comparing belatacept with tacrolimus after de novo kidney transplantation. Transplantation. 2017;101(10):2571-2581.

86. Cohen JB, Eddinger KC, Forder KA, et al. Belatacept compared to tacrolimus for kidney transplantation: a propensity score matched cohort study. Transplantation. 2017;101(10):2582-2589.

87. Wen X, Casey MJ, Santos AH, et al. Comparison of utilization and clinical outcomes for belatacept- and tacrolimus-based immunosuppression in renal transplant recipients. Am J Transplant. 2016;16(11):3202-3211.

88. Ferguson R, Grinyo J, Vincenti F, et al. Immunosuppression with belatacept-based, corticosteroid-avoiding regimens in de novo kidney transplant recipients. Am J Transplant. 2011;11:66-76.

89. Wojciechowski D, Chanadran S, Vincenti F. Early post-transplant conversion from tacrolimus to belatacept for prolonged delayed graft function improves renal function in kidney transplant recipients. Clin Transplant. 2017;31(5):e12930.

90. Dürr M, Lachmann N, Zukunft B, et al. Late conversion to belatacept after kidney transplantation: outcome and prognostic factors. Transplant Proc. 2017;49(8):1747-1756.

91. Ong P, Mudambi L, Fuentes A, et al. Belatacept as primary immunosuppression in a lung transplant recipient. J Heart Lung Transplant. 2014;33(S4):S31.

92. Mujtaba MA, Sharfuddin AA, Taber T, et al. Conversion from tacrolimus to belatacept to prevent the progression of chronic kidney disease in pancreas transplantation: a case report of two patients. Am J Transplant. 2014;14(11):2657-2661.

93. Enderby CY, Habib P, Patel PC, et al. Belatacept maintenance in a heart transplant recipient. Transplantation. 2014;98(7):e74-e75.

94. Klintmalm GB, Lake JR, Vargas HE, et al. Belatacept-based immunosuppression in de novo liver transplant recipients: 1-year experience from a phase II randomized study. Am J Transplant. 2014;14:1817-1827.
95. LaMattina JC, Jason MP, Hanish SI, et al. Safety of belatacept bridging immunosuppression in hepatitis C-positive liver transplant recipients with renal dysfunction. Transplantation. 2014;97:133-137.

96. Webster AC, Playford EG, Higgins G, Chapman JR, Craig JC. Interleukin 2 receptor antagonists for renal transplant recipients: a meta-analysis of randomized trials. Transplantation. 2004;77(2):166-176.

97. Kovarik JM, Moore R, Wolf $\mathrm{P}$, et al. Screening for basiliximab exposure-response relationships in renal allotransplantation. Clin Transplant. 1999;13:32.

98. Heffron TG, Smallwood GA, Pillen T, et al. Liver transplant induction trial of daclizumab to spare calcineurin inhibition. Transpl Proc. 2002;34:1514.

99. Yoshida EM, Marotta PJ, Greig PD, et al. Evaluation of renal function in liver transplant recipients receiving daclizumab (Zenapax), mycophenolate mofetil, and a delayed, low-dose tacrolimus regimen vs. a standard-dose tacrolimus and mycophenolate mofetil regimen: a multicenter randomized clinical trial. Liver Transpl. 2005;11:1064.

100. Neuberger JM, Mamelok RD, Neuhaus P, et al. Delayed introduction of reduced-dose tacrolimus, and renal function in liver transplantation: the 'ReSpECT' study. Am J Transplant. 2009;9:327.

101. Cantarovich M, Metrakos P, Giannetti N, Cecere R, Barkun J, Tchervenkov J. Anti-CD25 monoclonal antibody coverage allows for calcineurin inhibitor "holiday" in solid organ transplant patients with acute renal dysfunction. Transplantation. 2002;73(7):1169-1172.

102. Vincenti F, Grinyo J, Ramos E, et al. Can antibody prophylaxis allow sparing of other immunosuppressives? Transplant Proc. 1999;31:1246.

103. Kirchner VA, Suszynski TM, Radosevich DM, et al. Anti-CD25 antibody (daclizumab) maintenance therapy in pancreas transplantation. Transplant Proc. 2010;42(6):2003-2005.

104. Gabardi S, Catella J, Martin ST, et al. Maintenance immunosuppression with intermittent intravenous IL-2 receptor antibody therapy in renal transplant recipients. Ann Pharmacother. 2011;45(9):e48.

105. Halloran PF. Immunosuppressive drugs for kidney transplantation. N Engl J Med. 2004;351:2715-2729.

106. Hardinger K, Brennan D, Klein C. Selection of induction therapy in kidney transplantation. Transpl Int. 2013;26:662-672.

107. Book BK, Pescovitz MD, Agarwal A, et al. In vitro monitoring of in vivo development of human anti-thymoglobulin antibodies by ELISA. Transplant Proc. 2006;38(9):2869-2871.

108. Regan JF, Campbell K, Van Smith LE, et al. Sensitization following Thymoglobulin and Atgam rejection therapy as determined with a rapid enzyme-linked immunosorbent assay. US Thymoglobulin Multi-Center Study Group. Transplant Immunol. 1999;7(2):115-121.

109. Waldmann H. Development and clinical use of CAMPATH $1 \mathrm{H}$. Transplant Rev. 2003;17:S5-S7.

110. Gruessner RW, Kandaswamy R, Humar A, Gruessner AC, Sutherland DE. Calcineurin inhibitor- and steroid-free immunosuppression in pancreas-kidney and solitary pancreas transplantation. Transplantation. 2005;79(9):1184-1189.

How to cite this article: Jorgenson MR, Descourouez JL, Brady BL, et al. Alternatives to immediate release tacrolimus in solid organ transplant recipients: When the gold standard is in short supply. Clin Transplant. 2020;34:e13903. https:// doi.org/10.1111/ctr.13903 


\section{APPENDIX 1}

1 Currently available immediate-release (IR) tacrolimus (TAC) alternatives

\begin{tabular}{|c|c|c|c|}
\hline Options & Available Products $^{a}$ & Benefits compared to IR Tacrolimus & Drawbacks compared to IR Tacrolimus \\
\hline \multirow[t]{2}{*}{$\begin{array}{l}\text { Calcineurin } \\
\text { inhibitors (CNI) }\end{array}$} & $\begin{array}{l}\text { Advagraf }^{\circledR}(\text { ER TAC }) \\
\text { Astagraf } X L^{\circledR} \\
\text { (ER TAC) } \\
\text { Envarsus } \mathrm{XR}^{\circledR} \text { (LCPT) }\end{array}$ & $\begin{array}{l}\text { - Increased bioavailability } \\
\text { - Reduced serum concentration fluctuations } \\
\text { (note: not associated with improved TAC trough } \\
\text { variability) } \\
\text { - Once-daily drug administration } \\
\text { - Potential for improved medication adherence }\end{array}$ & $\begin{array}{l}\text { - FDA approval only in KTRs } \\
\text { - Possible payor coverage issues } \\
\text { - Pharmacokinetic (PK) differences } \\
\text { between products }\end{array}$ \\
\hline & $\begin{array}{l}\text { Cyclosporine } \\
\text { non-modified } \\
\text { (Sandimmune) } \\
\text { Cyclosporine } \\
\text { modified (Gengraf, } \\
\text { Neoral) }\end{array}$ & $\begin{array}{l}\text { - Possible reduced neurotoxicity } \\
\text { - Possible reduction in new-onset diabetes after } \\
\text { transplant (NODAT) }\end{array}$ & $\begin{array}{l}\text { - Increased PK variability } \\
\text { - May lower mycophenolic acid (MPA) } \\
\text { plasma concentrations } \\
\text { - PK differences between products } \\
\text { - Associated with increased risk of acute } \\
\text { rejection }\end{array}$ \\
\hline $\begin{array}{l}\text { Mammalian Target } \\
\text { of Rapamycin } \\
\text { Inhibitor } \\
\text { (MTOR-i) }\end{array}$ & $\begin{array}{l}\text { Sirolimus } \\
\left(\text { Rapamune }{ }^{\circledR}\right) \\
\text { Everolimus } \\
\left(\text { Zortress }^{\circledR}\right)\end{array}$ & $\begin{array}{l}\text { - Reduced nephrotoxicity } \\
\text { - Reduced malignancy } \\
\text { - Reduced risk of coronary allograft vasculopathy } \\
\text { (CAV) } \\
\text { - Reduced risk of viral infection (CMV, BK) } \\
\text { - Once-daily administration with sirolimus }\end{array}$ & $\begin{array}{l}\text { - Potential for impaired wound healing } \\
\text { and anastomotic dehiscence (avoid use in } \\
\text { first } 30 \mathrm{~d} \text { postop) } \\
\text { - High rates of intolerance (discontinuation } \\
\text { rates: } 17 \%-26 \% \text { ) proteinuria, } \\
\text { hyperlipidemia } \\
\text { - PK differences between products } \\
\text { - Associated with increased risk of acute } \\
\text { rejection }\end{array}$ \\
\hline $\begin{array}{l}\text { Costimulatory } \\
\text { blocker }\end{array}$ & Belatacept $\left(\right.$ Nulojix $\left.{ }^{\circledR}\right)$ & $\begin{array}{l}\text { Therapeutic drug monitoring (TDM) not required } \\
\text { Long half-life } \\
\text { Improved tolerance Limited adverse drug effects } \\
\text { (ADEs) } \\
\text { Avoids CNI-associated nephrotoxicity } \\
\text { Possible improved adherence }\end{array}$ & $\begin{array}{l}\text { - Requires IV administration } \\
\text { - Contraindicated in EBV-negative } \\
\text { recipients } \\
\text { - Avoid use in liver transplant } \\
\text { - Manufacturer's limited distribution } \\
\text { - Possible payor coverage issues } \\
\text { - Associated with increased risk of acute } \\
\text { rejection }\end{array}$ \\
\hline $\begin{array}{l}\text { Non-lymphocyte- } \\
\text { depleting agents }\end{array}$ & $\begin{array}{l}\text { Basiliximab } \\
\left(\text { Simulect }{ }^{\circledR}\right)\end{array}$ & $\begin{array}{l}\text { - TDM not required } \\
\text { - Long half-life } \\
\text { - Limited ADEs }\end{array}$ & $\begin{array}{l}\text { - Requires IV administration } \\
\text { - Limited supporting data } \\
\text { - Possible payor coverage issues } \\
\text { - Associated with increased risk of acute } \\
\text { rejection }\end{array}$ \\
\hline $\begin{array}{l}\text { Lymphocyte- } \\
\text { depleting agents }\end{array}$ & $\begin{array}{l}\text { Rabbit anti- } \\
\text { thymocyte globulin } \\
\text { (rATG) } \\
\text { Alemtuzumab } \\
\text { (Campath }{ }^{\circledR} \text { ) }\end{array}$ & $\begin{array}{l}\text { - TDM not required } \\
\text { - Possible reduction of CNI-related ADEs }\end{array}$ & $\begin{array}{l}\text { - Requires intravenous administration } \\
\text { - No literature supporting rATG } \\
\text { - Single study supporting alemtuzumab } \\
\text { - Increased infectious and malignant risk } \\
\text { - Use requires careful patient selection }\end{array}$ \\
\hline
\end{tabular}

Note: This table summarizes literature referenced in this manuscript and is not inclusive of all published studies supporting drug utilization in these allograft subtypes

${ }^{a}$ For additional details, refer to the individual products prescribing guidelines. 
Studies Reviewed with pertinent efficacy and safety findings per organ type. Study type categorized as (A) Randomized Controlled Trial or (B) Non-Randomized Controlled Trial

\begin{tabular}{|c|c|c|c|c|c|}
\hline Kidney-De Novo & Kidney-Conversion & Heart & Lung & Liver & Pancreas \\
\hline (A) Silva 2014 & (A) Alloway 2014 & (B) González-Vílchez 2014 & (B) Soto 2015 & (A) Dubay 2019 & (B) Dib 2018 \\
\hline (A) Budde 2014 & (B) Saengram 2018 & (B) González-Vílchez 2015 & (B) Helena 2018 & (A) Trunecka 2010 & (B) Kerstenetzky \\
\hline (A) Rostaing 2016 & (A) Bunnapradist 2016 & (B) González-Vílchez 2018 & (B) Méndez 2014 & (B) Alloway 2014 & 2018 \\
\hline (B) Bunnapradist & (B) Bunnapradist 2016 & & (B) Etienne 2014 & (B) Altieri 2018 & \\
\hline
\end{tabular}

2016

(B)Oh 2019

(B) Webster 2005

(A) Ekberg 2007

(B) Kramer 2008

(A) Grinyo 2009
(A) Ye 2008

(A) Fan 2009

(B) Muduma 2016

(A) Saudek 2005
(B) Morath 2007
(A) Flechner 2004
(A) Hamdy 2005
(A) Budde 2011
(A) Ekberg 2007
(B) Morath 2007
(B) Karpe 2017
(A) Schena 2009
(A) Mjornstedt 2015
(A) Lebranchu 2009
(A) Weir 2011
(A) Guba 2010
(A) Heilman 2011
(A) Zuckerman 2012
(B) Groetzner
(A) De Simone 2012
(B) Matias 2008
(A) Groetzner 2009
(A) Andreassen 2016
(A) Teperman 2013
(A) Andreassen 2014
(B) Lischke 2006
(B) King-Biggs
(A) Glover 2016
$\begin{array}{ll}\text { (B) King-Biggs } & \text { (A) Saliba } 2016\end{array}$
2003
(A) Fischer 2012
(B) Tang 2015

(A) Lintmalm 2014

(B) LaMattina 2014
(B) Mujtaba 2014
(A) Vincenti 2010

(B) Pestana 2012

(A) De Graav 2017

(A) Ferguson 2011

(B) Wen 2016

(B) Cohen 2017

\section{(B) Nair 2017}

(A) Grinyo 2016

(B) Wojciechowski 2017

(B) Durr 2017

(B) Enderby 2014

(B) Ong 2014
(B) Webster 2004
(B) Cantarovich 2002
(B) Vincenti 1999
(B) Gabardi 2011

(B) Cantarovich 2002
(A) Neuberrger 2009
(B) Cantarovich 2002 